\title{
Risk Evaluation System of Utility Tunnel PPP Project Research Based on Fuzzy Comprehensive Evaluation Method
}

\author{
Yihua Mao ${ }^{1, \mathrm{a}}$ and Yaoyao Zhang $^{1, \mathrm{~b}}$ \\ ${ }^{1}$ College of Civil Engineering and Architecture, Zhejiang University, Hangzhou 310000, China \\ azjumyh@163.com, b1017306406@qq.com
}

Keywords: utility tunnel, PPP, risk evaluation, fuzzy comprehensive evaluation method.

\begin{abstract}
In this paper, risks of the utility tunnel PPP project are identified through the literature research and expert interviews. Then fuzzy comprehensive evaluation method is used to establish the evaluation model, which quantifies the qualitative index and achieve the multi-faceted comprehensive evaluation of the project, so as to provide reference for the later academic research and practical activities.
\end{abstract}

\section{Introduction}

The utility tunnel refers to the public tunnel for the centralized laying of communications, radio and television, electricity, water supply and sewerage, drainage, heat, gas and other municipal pipelines. It is conducive to the unified planning and management of municipal pipelines and solves the problems of "road zipper", "spider web" and so on. It can also protect urban security, improve urban functions, beautify the urban landscape and promote urban intensive and efficient development. Moreover, it can broaden the channels of social capital investment. Therefore, the construction of utility tunnel is inevitable requirement of social development.

In recent years, the government has vigorously promoted the construction of utility tunnel. In order to solve the problem of large investment, the government issued a series of policies to attract social capital investment, and actively promote the application of PPP mode. However, the application of the PPP model in the utility tunnel is still in its infancy, and there must be a variety of risks. So how to effectively identify and control the risk factors becomes the difficulty.

\section{Literature Review}

At present, the research on the risk of utility tunnel PPP project is still limited, which is mainly at the stage of qualitative analysis. And the research on risk assessment is almost blank. However, scholars have done a lot of research on PPP project risk assessment, among them fuzzy comprehensive evaluation method is the most widely used and often used in conjunction with analytic hierarchy process (AHP). T. Qin, Y. R. He and L. Bai [1] classified the potential risk factors of the PPP project into first index (5 items) and the second index (17 items), then used the fuzzy comprehensive evaluation method to quantify the risk factors, constructed the risk management function model and determined the risk level. Y. L. Xu, A. P. C. Chan and J. F. Y. Yeung [2] identified 23 principles and influencing factors for risk and evaluated them using the fuzzy comprehensive evaluation method. B. Chen and Y. F. Li [3] took business risk, construction risk and operation risk and policy risk as an analysis object, then established the AHP evaluation index system and use fuzzy model analytic hierarchy evaluation model to evaluate the risk of urban rail transit projects construction, finally concluded that legal policy risk was the primary precautionary point for urban rail transit construction projects financing in PPP mode. $\mathrm{H}$. Li and X. Xu [4] also established a fuzzy comprehensive evaluation model to assess risks for the implementation process of the PPP project. In a word, the fuzzy comprehensive evaluation method means that use fuzzy mathematics and fuzzy statistical methods to make a scientific evaluation of the merits and demerits of the thing through a comprehensive consideration of the impact of all factors [5]. It is an effective comprehensive evaluation method. 


\section{Fuzzy Comprehensive Evaluation Model}

\subsection{Determine the Factor Set}

The factor set $R$ is the collection of evaluation indicators. Let $R=\left\{R_{1}, R_{2}, \cdots, R_{m}\right\}$. First grade indexes can be classified into second grade indexes. So suppose that $R_{i}$ is reflected by $n$ secondary indexes, then $R_{i}=\left\{R_{i 1}, R_{i 2}, \cdots, R_{i n}\right\}(i=1,2, \cdots, m)$. We will establish a systematic and comprehensive evaluation index system of utility tunnel PPP project in the following.

\subsection{Determine the Index Weight}

The determination of the weight of the evaluation index plays an important role in the objective reflection of the risk status of the underground utility tunnel PPP project. In this paper, AHP is used to determine the index weight. This method is firstly put forward by A. L. Saaty (1971), the famous American operational research scientist, at the first international mathematical modeling conference.

\subsubsection{Construct the Judgment Matrix}

The experts compare the elements in each layer to construct a comparative judgment matrix and to quantify the relative importance of the relative importance of the next level factor for the upper level factor with reference to the scale table proposed by Professor T. L. Saaty. The values and meanings of the numbers are shown in Table 1, where the two elements are assumed to be $\mathrm{i}$ and $\mathrm{j}$, and the relative weight is $a_{i j}$.

Table 1 Judgment Matrix Scale

\begin{tabular}{|c|c|}
\hline Scale & Meaning \\
\hline 1 & The factor $\mathrm{i}$ is as important as the factor $\mathrm{j}$. \\
\hline 3 & The factor $\mathrm{i}$ is slightly more important than the factor $\mathrm{j}$. \\
\hline 5 & The factor $\mathrm{i}$ is more important than the factor $\mathrm{j}$. \\
\hline 9 & The factor $\mathrm{i}$ is much more important than the factor $\mathrm{j}$. \\
\hline $2,4,6,8$ & They represent the intermediate point of adjacent judgments. \\
\hline Reciprocal & $\begin{array}{c}\text { If the factor } \mathrm{i} \text { is compared to the factor } \mathrm{j} \text {, the judgment value is } a_{i j}, \text { then } \\
a_{j i}=1 / a_{i j} .\end{array}$ \\
\hline
\end{tabular}

According to the scale table, judgment matrix A can be constructed:

$$
A=\left[\begin{array}{cccc}
1 & a_{12} & \cdots & a_{1 m} \\
a_{21} & 1 & \cdots & a_{2 m} \\
\vdots & \vdots & \ddots & \vdots \\
a_{m 1} & a_{m 2} & \cdots & 1
\end{array}\right]
$$

\subsubsection{Use Sum-Product Method to Solve Judgment Matrix}

(1) Normalize each column element of the judgment matrix.

$$
\overline{a_{i j}}=\frac{a_{i j}}{\sum_{i=1}^{m} a_{i j}}(i, j=1,2, \cdots, m)
$$

(2)Then the judgment matrix is added in rows, and the row vectors are normalized to obtain the eigenvector $W$.

3.2.3 Consistency Check

Calculate the largest characteristic root of the judgment matrix and bring it into equation (3) to test its consistency.

$$
\lambda_{\max }=\frac{1}{m} \sum_{i=1}^{m} \frac{\left(A W_{i}\right)}{W_{i}}
$$




$$
C R=\frac{C I}{R I}, C I=\frac{\lambda_{\max }-m}{m-1}
$$

When $C R<0.1$, it is considered that the consistency of the judgment matrix is acceptable; when $C R<0.1$, it is necessary to adjust the relative importance of the $\mathrm{i}$ element and the $\mathrm{j}$ element in the matrix until $C R<0.1$.

\subsection{Determine the Comment Set}

$V=\left(v_{1}, v_{2}, \ldots, v_{N}\right)$ represents the $\mathrm{N}$ evaluation grades of each factor, which specifies the range of evaluation results for a factor. $\mathrm{N}$ is an odd number in [3,7]. In this paper, $\mathrm{N}$ is equal to 5 , and each evaluation grade represents the extent to which each risk factor affects the project.

\subsection{Determine the Membership Matrix}

The key of the fuzzy comprehensive evaluation method is to analyze the membership degree of each factor in the evaluation factor set for each evaluation grade, so as to get the evaluation result of the single factor [6].

Assuming that the $\mathrm{i}$-th evaluation factor is $R_{i}$, the single factor evaluation result is $X_{i}=\left(x_{i 1}, x_{i 2}, \cdots x_{i N}\right)$, and $x_{i j}$ is the membership degree of the $\mathrm{i}$-th evaluation factor $R_{i}$ to the $\mathrm{j}$-th grade. If the m elements are evaluated, finally we will obtain the membership matrix of the m rows and N columns, where $x_{i j}$ can be determined by:

$$
x_{i j}=\frac{d_{i j}}{d}
$$

$d_{i j}$ is the number of people who give the index $R_{i}$ evaluation grade $\mathrm{j}$, and $\mathrm{d}$ indicates the total number of experts.

\subsection{Fuzzy Synthesis Calculation and Comprehensive Evaluation}

By multiplying the fuzzy weight vector with the membership matrix, we can obtain the membership degree of the evaluation factor as a whole for each evaluation grade. Then we can determine the evaluation level of the evaluation object, and give the evaluation conclusion according to the principle of maximum membership degree, or we can calculate the total score of the project.

\section{Case Analysis}

We assume a case of utility tunnel PPP project that will use the evaluation model.

\subsection{Constructing Evaluation Index System.}

The utility tunnel PPP project has the characteristics of large investment, long construction period and many stakeholders, so there are many risk factors in the process. In this paper, 39 risk factors are identified as the risk indexes through literature review and expert interviews. At the same time, they are classified according to the nature of risk and divided into political and environmental risk, technical risk, construction risk, market risk, financing risk and management risk. See Table 2 for details.

Table 2 Risk Factors of Utility Tunnel PPP project

\begin{tabular}{|c|c|c|}
\hline Target Layer & Criterion Layer & Index Layer \\
\hline \multirow{4}{*}{$\begin{array}{c}\text { Risk of Utility Tunnel } \\
\text { PPP Project } \\
\mathrm{R}\end{array}$} & Political and & Legal Supporting Situation $\mathrm{R}_{11}$ \\
\cline { 3 - 3 } & Environmental Risk & Macroeconomic Situation $\mathrm{R}_{12}$ \\
\cline { 3 - 3 } & $\mathrm{R}_{1}$ & Continuity of Good Policy $\mathrm{R}_{13}$ \\
\cline { 3 - 3 } & & Land Acquisition $\mathrm{R}_{14}$ \\
\cline { 3 - 3 } & & Rationality of Planning $\mathrm{R}_{15}$ \\
\cline { 3 - 3 } & & Social Stability $\mathrm{R}_{16}$ \\
\cline { 3 - 3 } & & Approval $\mathrm{R}_{17}$ \\
\cline { 3 - 3 } & & Land Property Rights $\mathrm{R}_{18}$ \\
\cline { 3 - 3 } & Financing Risk & Change of Interest $\mathrm{R}_{21}$ \\
\hline
\end{tabular}




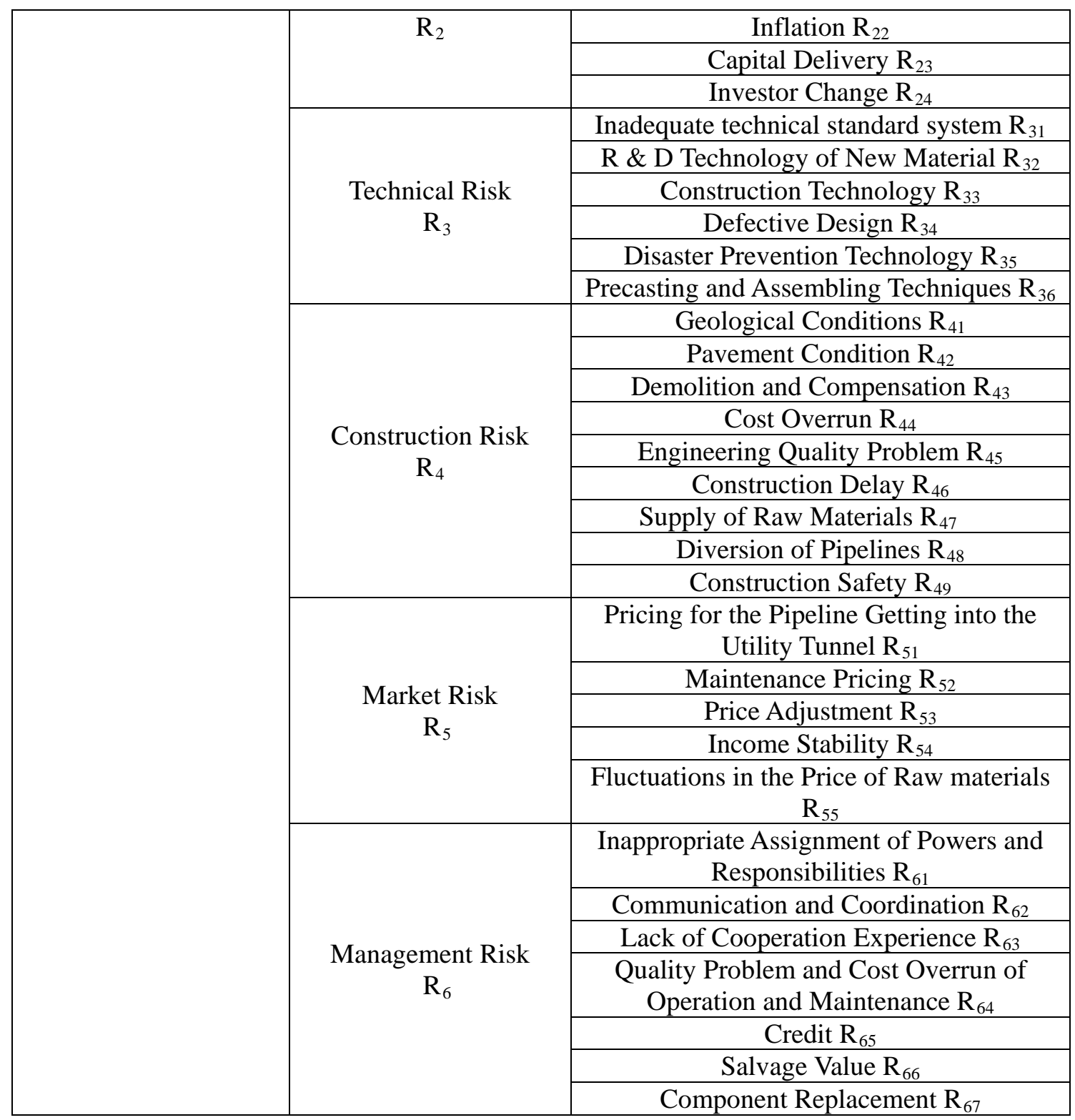

\subsection{Determine the Index Weight and Test the Consistency}

Based on the AHP, 20 experts are invited to compare the importance of the evaluation factors according to the 1-9 scale, and we obtain the judgment matrix: $R-R_{i}, R_{1}-R_{1 j}, R_{2}-R_{2 j}$, $R_{3}-R_{3 j}, R_{4}-R_{4 j}, R_{5}-R_{5 j}, R_{6}-R_{6 j}$. Then calculate the index weight according to the judgment matrix, and test its consistency. In case of passing consistency check, the final weight of each element is:

$$
\begin{aligned}
& W=(0.0732,0.3576,0.0324,0.1254,0.2057,0.2057) \\
& W_{1}=(0.0382,0.2143,0.3778,0.0382,0.0995,0.0969,0.0382,0.0969) \\
& W_{2}=(0.0704,0.0704,0.3221,0.5371) \\
& W_{3}=(0.1025,0.1025,0.3082,0.2855,0.1544,0.0470) \\
& W_{4}=(0.0948,0.0414,0.0409,0.0414,0.2771,0.0256,0.0256,0.0948,0.3583) \\
& W_{5}=(0.3474,0.1202,0.1202,0.3474,0.0648) \\
& W_{6}=(0.1743,0.0417,0.0417,0.2679,0.3741,0.0739,0.0265)
\end{aligned}
$$

$W$ denotes the index weight in the criterion layer, and $W_{i}(i=1,2, \cdots, 6)$ is the index weight in the index layer. 


\subsection{Construct the Comment Set}

After determining the factor set and the index weight, we need to determine the comment set. In this paper, the evaluation grades are divided according to the degree of influence of each risk factor on the project. The meanings of the specific division method and the each evaluation grade are shown in Table 3.

Table 3 Risk Assessment

\begin{tabular}{|c|c|}
\hline Evaluation Grade & Risk Impact \\
\hline$[0,1]$ & Very Little \\
\hline$(1,2]$ & Little \\
\hline$(2,3]$ & Medium \\
\hline$(3,4]$ & Great \\
\hline$(4,5]$ & Very Great \\
\hline
\end{tabular}

\subsection{Determine the Membership Degree of Each Evaluation Factor}

20 experts evaluate the risk grade of each factor according to the above risk assessment criteria. And we get membership matrix as follows:

$$
\begin{aligned}
& X_{1}=\left(\begin{array}{rrrrr}
0 & 0.15 & 0.3 & 0.4 & 0.15 \\
0 & 0.1 & 0.25 & 0.5 & 0.15 \\
0 & 0.15 & 0.15 & 0.3 & 0.4 \\
0.15 & 0.25 & 0.5 & 0.1 & 0 \\
0.1 & 0.25 & 0.4 & 0.25 & 0 \\
0.2 & 0.25 & 0.3 & 0.2 & 0.05 \\
0.1 & 0.4 & 0.35 & 0.15 & 0 \\
0.1 & 0.3 & 0.5 & 0.1 & 0
\end{array}\right) \quad X_{4}=\left(\begin{array}{rrrrr}
0 & 0.15 & 0.3 & 0.4 & 0.15 \\
0.1 & 0.15 & 0.45 & 0.3 & 0 \\
0.05 & 0.25 & 0.5 & 0.2 & 0 \\
0 & 0.15 & 0.3 & 0.55 & 0 \\
0 & 0.05 & 0.15 & 0.45 & 0.35 \\
0 & 0.25 & 0.6 & 0.15 & 0 \\
0.15 & 0.25 & 0.35 & 0.25 & 0 \\
0 & 0.15 & 0.3 & 0.4 & 0.15 \\
0 & 0.1 & 0.2 & 0.3 & 0.4
\end{array}\right) \\
& X_{2}=\left(\begin{array}{rrrrr}
0 & 0.15 & 0.15 & 0.4 & 0.3 \\
0 & 0.25 & 0.35 & 0.2 & 0.2 \\
0 & 0.2 & 0.3 & 0.4 & 0.1 \\
0 & 0.15 & 0.2 & 0.3 & 0.35
\end{array}\right) \\
& X_{5}=\left(\begin{array}{rrrrr}
0 & 0.15 & 0.25 & 0.45 & 0.15 \\
0 & 0.1 & 0.25 & 0.4 & 0.25 \\
0.1 & 0.2 & 0.4 & 0.3 & 0 \\
0 & 0.05 & 0.25 & 0.45 & 0.25 \\
0.05 & 0.25 & 0.45 & 0.25 & 0
\end{array}\right) \\
& X_{3}=\left(\begin{array}{rrrrr}
0 & 0.1 & 0.3 & 0.4 & 0.2 \\
0.1 & 0.4 & 0.4 & 0.1 & 0 \\
0 & 0.1 & 0.2 & 0.4 & 0.3 \\
0 & 0.2 & 0.35 & 0.4 & 0.05 \\
0 & 0.2 & 0.4 & 0.3 & 0.1 \\
0.2 & 0.2 & 0.35 & 0.25 & 0
\end{array}\right) \\
& X_{6}=\left(\begin{array}{rrrrr}
0 & 0.15 & 0.2 & 0.4 & 0.25 \\
0 & 0.1 & 0.25 & 0.45 & 0.2 \\
0 & 0.2 & 0.25 & 0.5 & 0.05 \\
0 & 0.05 & 0.25 & 0.6 & 0.1 \\
0 & 0.35 & 0.35 & 0.3 & 0 \\
0.05 & 0.2 & 0.45 & 0.3 & 0 \\
0.15 & 0.2 & 0.5 & 0.15 & 0
\end{array}\right)
\end{aligned}
$$

\subsection{Fuzzy Comprehensive Evaluation}

Multiply the evaluation matrix of risk index (second index) and the weight of the evaluation index to obtained evaluation matrix of evaluation index (secondary index) in criterion layer, where $B_{\mathrm{i}}=W_{i} X_{i}$.

$$
\begin{aligned}
& B_{1}=(0.0486,0.1868,0.2715,0.2993,0.1938) \\
& B_{2}=(0.0000,0.1731,0.2393,0.3322,0.2554)
\end{aligned}
$$




$$
\begin{aligned}
& B_{3}=(0.0196,0.1794,0.3115,0.3468,0.1427) \\
& B_{4}=(0.0100,0.1136,0.2460,0.3617,0.2688) \\
& B_{5}=(0.0153,0.1217,0.2810,0.4130,0.1690) \\
& B_{6}=(0.0077,0.2031,0.3001,0.4084,0.0808)
\end{aligned}
$$

In the same way, multiply the index weight of the criterion layer and evaluation weight to obtain the evaluation matrix of the target layer:

$$
B=W X=(0.0102,0.1625,0.2659,0.3663,0.1952)
$$

In order to get the project risk score (the total risk profile of the project), we take the median of each evaluation grade to get the vector $K=(0.5,1.5,2.5,3.5,4.5)$. So the comprehensive score is:

$$
P=B K^{T}=3.0739
$$

We can find that the project has the highest membership degree for the risk level $(3,4]$ from $B$. The overall score of 3.0739 also shows that the project risk is at a high level.

\section{Conclusions}

In this paper, we construct the evaluation index system according to the characteristics of utility tunnel PPP project, and establish the evaluation model by using fuzzy comprehensive evaluation method to evaluate project risk. In the evaluation process, we also use AHP to determine the weight of indexes. Through risk assessment, we can understand all kinds of project risks, as well as the project's comprehensive risk value, so as to broaden the thinking of the research on utility tunnel PPP project, and also provide effective reference for actual project.

\section{References}

[1] T. Qin, Y.R. He and L. Bai, Construction of PPP Mode Risk Management Model Based on Fuzzy Comprehensive Evaluation Method. Editorial Department of Tangshan College, 2016. 29(3): p. 84-87.

[2] Y.L. Xu, A.P.C. Chan and J.F.Y. Yeung, Developing a Fuzzy Risk Allocation Model for PPP Projects in China. Journal of Construction Engineering \& Management, 2010. 136(8): p. 894-903.

[3] B. Chen and Y.F. Li, Application of Fuzzy Comprehensive Evaluation Method in PPP Project Risk Assessment. Technology \& Economy in Areas of Communications, 2008(01): p. 119-121.

[4] H. Li and X. Xu, Research on Fuzzy Comprehensive Evaluation Method of PPP Project Risk Based on Entropy Weight. Market Modernization, 2008(3): p. 170-171.

[5] L.N. Zhang, Application of AHP-Fuzzy Comprehensive Evaluation Method in Assessment of Eco-industrial Park, 2006, Dalian University of Technology.

[6] J.F. Lin, Study on Risk Identification and Evaluation of China's Alternative Fuel Vehicle Industry, 2015, Harbin Engineering University. 